for the stimulus and help of many discussions with them on the epidemiology of Burkitt's tumour. Miss Serina Joyce saw the data through all the stages of analysis with the London University ICT Atlas Computer in a manner impossible to improve upon, and for this we are extremely grateful. Finally, we would like to thank Mrs. Z. Pereira for her secretarial assistance in the collection of the data and in the preparation of this report, and $\mathrm{Mr}$. W. Serumaga, of the department of medical illustration, Makerere Medical School, for drawing the figures.

Dr. E. H. Williams is grateful for the financial help given to him by the East African Medical Research Council for general and travel expenses involved in this study.
REFERENCES

Bell, T. M., Massie, A., Ross, M. G. R., and Williams, M. C. (1964). Brit. med. Ұ., 1, 1212 .

Burkitt, D. (1962). Postgrad. med. 7., 38, 71.

-

David, F. N., and Barton, D. E. (1966). Brit. F. prev. soc. Med., 20, 44.

Eavid, F. N., and Barton, D. E. (1966). Brit. F. prev. soc. Med., 20, 702. Epstein, M. A.̈. Achong, B. G., and Barr, Y. M. (196.

Goma, L. K. H. (1965). E. Afr. med. 7., 42, 62.

Knox, G. (1964). Ibid., 18, 17.

Simons, P. J., and Ross, M. G. R. (1963). A.R. imp. Cancer Res. Fd, p. 48.

Streissle, G., and Maramorosch, K. (1963). Science, 140, 996.

Woodall, J. P., and Haddow, A. J. (1962). E. Afr. Virus Res. Inst. Rep., p. 30 .

\title{
Bronchodilator Response Patterns in Patients with Chronic Airways Obstruction: Use of Peak Inspiratory Flow Rate
}

\author{
K. B. SAUNDERS,* M.A., M.D., M.R.C.P.
}

Brit. med. F., 1967, 2, 399-402

In pulmonary disease with airways obstruction the effect of bronchodilator therapy is commonly assessed by simple measurements of ventilatory function, most of which require a maximal expiratory effort by the patient.

During expiration in the normal subject the airways tend to become narrower with increasing transpulmonary pressure: during inspiration they tend to widen (Fry and Hyatt, 1960). In diffuse airways obstruction there may be gross narrowing or collapse of airways on expiration (Dayman, 1951). Macklem et al. (1965) point out that in some patients the effect of bronchodilator drugs might not be detected by tests involving maximal expiratory effort, since collapse of large central airways might mask the effect of relief of spasm in small peripheral bronchi.

An attempt is made here to compare response to a bronchodilator drug by means of both peak expiratory flow (P.E.F.R.) and peak inspiratory flow rate.(P.I.F.R.), and to correlate changes in these variables with changes in forced expiratory volume in one second (F.E.V..) and forced vital capacity (F.V.C.). The response patterns in patients with and without radiological evidence of emphysema are compared.

\section{Subjects}

Thirty patients with chronic diffuse airways obstruction were studied. All complained of shortness of breath and 26 had chronic cough with sputum. All had values for F.E.V. $/$ F.V.C. of less than $70 \%$; all but two had a P.E.F.R. of less than $3001 . / \mathrm{min}$. All were receiving some form of bronchodilator therapy, which was omitted on the day of lung-function tests.

\section{Methods}

Measurement of Peak Flow Rates.-P.E.F.R. and P.I.F.R. were measured with a Wright peak flow meter (Wright and - McKerrow, 1959), adapted, as suggested by Nairn and McNeill (1963), by fitting a backpiece with central orifice to take the usual mouthpiece. It was calibrated against steady flows from a glass rotameter (Rotameter Manufacturing Co. Ltd.) over a range of $60-3501 . / \mathrm{min}$. This was done in two ways. (1) By blowing air through the meter (as for recording P.E.F.R.)

- Lecturer, Department of Medicine, St. Thomas's Hospital, London S.E.1. (a) with the backpiece on, and (b) with the backpiece removed. There was no significant difference between the calibration curves thus produced (Fig. 1). (2) By sucking air through the meter via a connexion on to the backpiece (as for recording P.I.F.R.). For this calibration the readings obtained on the Wright flow meter were consistently slightly higher for a given rotameter reading than those recorded in the previous two calibrations (Fig. 1). The difference was constant throughout the whole range, and was between 5 and $101 . / \mathrm{min}$. A value of $51 . / \mathrm{min}$. was therefore subtracted from all P.I.F.R. measurements. The meter was also checked against the master instrument used for calibration by the manufacturers.

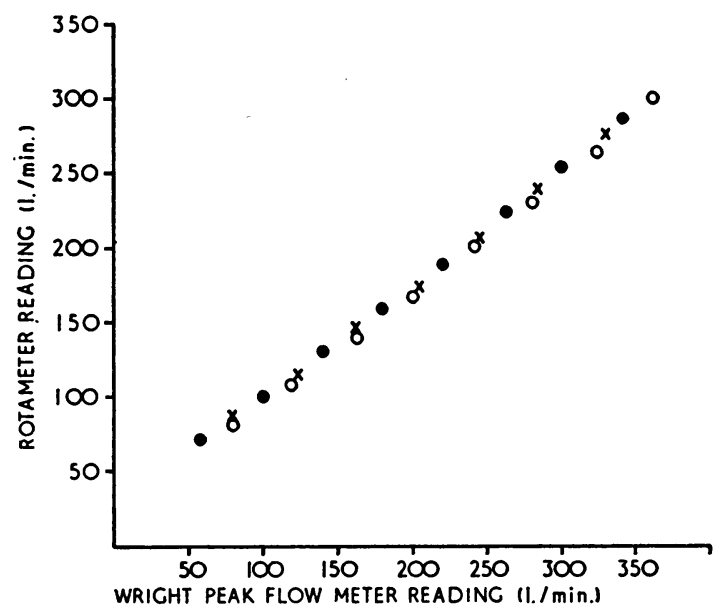

FIG. 1.-Calibration of adapted Wright peak flow meter - Air blown through flow meter; back piece on. $\times$ Air blown through flow meter; back piece off. $O$ Air sucked through flow meter via connexion to backpiece.

Spirometry.-F.E.V., and F.V.C. were measured with a dry spirometer (Collins et al., 1964).

Procedure.-Each patient practised the three manœuvres until familiar with them. Three readings of F.E.V. $\cdot_{1}$ and F.V.C. were then made, followed by five readings of P.E.F.R. and five of P.I.F.R. Some patients recorded P.E.F.R. before P.I.F.R. and some in the reverse order, the choice of order being randomized. A period of one minute was allowed between each recording of F.E.V. and F.V.C., and a period of 30 seconds between each recording of P.E.F.R. or P.I.F.R. The means of the two highest readings of F.E.V.. and F.V.C. and of the 
three highest readings of P.E.F.R. and P.I.F.R. were calculated. Then $1 \%$ isoprenaline B.P.C. was given by inhalation from a Dautrebande D30 generator (Dautrebande and Lovejoy, 1961) for two minutes, the measurements being repeated five minutes later.

Radiological Assessment.-The chest $x$-ray films of all subjects were examined by an independent observer (Dr. J. W. Pierce) and assessed for the presence of emphysema, with particular reference to the nature of peripheral vascular markings (Laws and Heard, 1962). The $x$-ray films were divided into three groups: (1) no evidence of emphysema (12 patients), (2) possible emphysema (6 patients), and (3) definite emphysema (12 patients). Each film was assessed on two different occasions, the observer being unaware both of the results of lung-function tests and (during the second assessment) of his previous grading of the film. Assessment varied on the two occasions in six patients by one grade; the lower grade was accepted.

Statistical Methods.-Analysis of variance was performed according to methods described by Snedecor (1956).

\section{Results}

Variability in Measurement of P.E.F.R. and P.I.F.R.-Table I shows the standard deviations (S.D.) for "within-patient" variance over serial ranges of P.E.F.R. and P.I.F.R., the highest three of each group of five readings being used. Values from three patients are omitted because they did not produce three readings of more than $60 \mathrm{l} . / \mathrm{min}$., which is the lowest recordable flow on the meter. For ranges of more than $150 \mathrm{l} . / \mathrm{min}$. where comparison is possible there was greater "withinpatient" variance in P.I.F.R. than in P.E.F.R. For two comparisons in the 0-99 and 100-149 ranges the reverse was true.

Effect of Isoprenaline on P.E.F.R. and P.I.F.R. (Fig. 2).-In 19 of the 30 subjects there was a greater increase in P.I.F.R. than in P.E.F.R. There was no significant correlation between change in P.I.F.R. and change in P.E.F.R. $(r=0.21, P>0.25)$.

Effect of Isoprenaline on F.E.V..$_{1}$ F.V.C.F.E.V./F.V.C. fell in 13 patients, was unchanged in 5, and was increased in 12 . The falls were caused by a disproportionate rise in F.V.C. rather than a decrease in F.E.V., after isoprenaline. Where F.E.V. $/$ F.V.C. increased, it was caused by a disproportionate rise in F.E.V..$_{1}$ rather than a fall in F.V.C

Correlation of Changes in P.E.F.R. and P.IF.R. with Changes in F.E.V., and F.V.C. (Fig. 3).-Change in P.E.F.R. after isoprenaline was significantly correlated with change in F.E.V., but not with change in F.V.C. Conversely, change in P.I.F.R. was significantly correlated with change in F.V.C. but not with change in F.E.V.. .

Relation of Radiological Emphysema to Type of Bronchodilator Response (Table II). - Mean values for the various lung-function tests were significantly worse in the patients with radiological emphysema (group 3). In patients without radiological emphysema (group 1) there was a significant increase in P.E.F.R., P.I.F.R., F.E.V. ${ }_{1}$, and F.V.C. after isoprenaline. F.E.V. ${ }_{1}$ /F.V.C. and P.E.F.R./P.I.F.R. tended to increase. In emphysematous patients there was a significant increase in P.I.F.R. and F.V.C., but not in P.E.F.R. and F.E.V.. F.E.V. ${ }_{1}$ F.V.C. tended to fall, and there was a significant decrease in P.E.F.R./P.I.F.R.

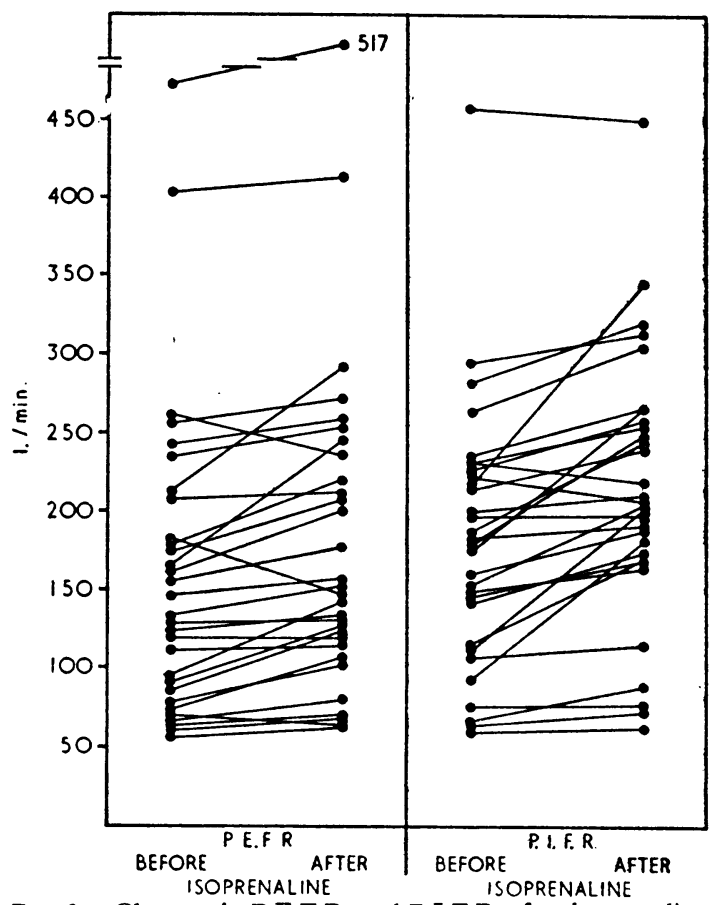

Fig. 2.- Changes in P.E.F.R. and P.I.F.R. after isoprenaline.
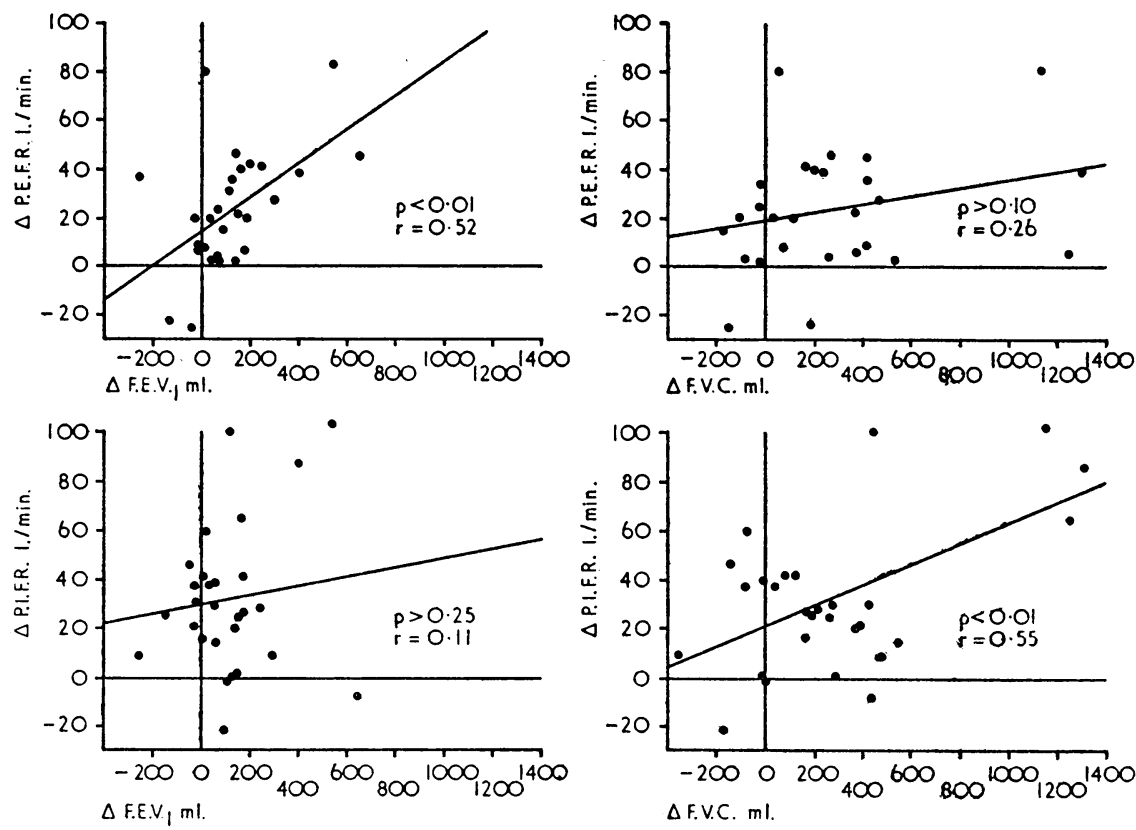

FIG. 3.-Correlations between change in P.E.F.R. and P.I.F.R., and change in F.E.V., and F.V.C.

\begin{tabular}{|c|c|c|c|c|c|c|c|c|c|}
\hline & \multicolumn{8}{|c|}{ Range of Mean P.E.F.R. or P.I.F.R. (1./min.) } & \multirow{2}{*}{$\begin{array}{l}\text { Mean } \\
\text { Values }\end{array}$} \\
\hline & $0-99$ & $100-149$ & $150-199$ & $200-249$ & $250-299$ & $300-349$ & $350-399$ & 400 & \\
\hline $\begin{array}{l}\text { P.F.R. before isoprenaline. } \\
\text { T.F.R. before isoprenaline. } \\
\text { P.F.R. after isoprenaline } \\
\text { P.F.R. after isoprenaline }\end{array}$ & $\begin{array}{l}6.91 \quad(7) \\
4.98 \text { (2) } \\
7.27(2)\end{array}$ & $\begin{array}{c}12 \cdot 50(6) \\
9 \cdot 31(7) \\
11 \cdot 15 \text { (10) }\end{array}$ & $\begin{array}{r}17 \cdot 05(6) \\
22 \cdot 68(7) \\
6 \cdot 15(3) \\
13 \cdot 14(9)\end{array}$ & $\begin{array}{r}9 \cdot 03(6) \\
14.35(7) \\
11 \cdot 89(8) \\
23.27(7)\end{array}$ & $\begin{array}{r}13.63(3) \\
5.51(2) \\
14.95(4)\end{array}$ & $6 \cdot 73(4)$ & & $\begin{array}{l}9 \cdot 57(2) \\
7 \cdot 23(2)\end{array}$ & $\begin{array}{l}169 \\
194 \\
187 \\
231\end{array}$ \\
\hline
\end{tabular}


TABLE II.-Changes in Mean Values After Isoprenaline in Patients With and Without Radiological Evidence of Emphysema. N.S. =Not Significant $(P=0.05)$. The significance of the Effect of Isoprenaline Significant $(P=0.05)$. The significance
was Assessed by Analysis of Variance

\begin{tabular}{|c|c|c|c|c|}
\hline & Mean Values of & $\begin{array}{c}\text { Before } \\
\text { Iso- } \\
\text { prenaline }\end{array}$ & $\begin{array}{c}\text { After } \\
\text { Iso-: } \\
\text { prenaline }\end{array}$ & $P$ \\
\hline $\begin{array}{l}\text { Group 1. No } \\
\text { emphysema, } \\
12 \text { patients }\end{array}$ & $\begin{array}{l}\text { F.E.V.1 (ml.) } \\
\text { F.V.C. (ml.) } \\
\text { P.E.F.R. (l./min.) } \\
\text { P.I.P.R. (l./min.) } \\
\text { F.E.V.1/F.V.C. (\%) } \\
\text { P.E.F.R./P.I.F.R. (\%) }\end{array}$ & $\begin{array}{r}1,161 \\
2,463 \\
174 \\
187 \\
47 \\
93\end{array}$ & $\begin{array}{r}1,316 \\
2,679 \\
196 \\
207 \\
49 \\
95\end{array}$ & $\begin{array}{l}<0.01 \\
<0.01 \\
<0.01 \\
<0.05 \\
\text { N.S. } \\
\text { N.S. }\end{array}$ \\
\hline $\begin{array}{l}\text { Group } 3 . \\
\text { Emphysema, } \\
12 \text { patients }\end{array}$ & $\begin{array}{l}\text { F.E.V.1 (ml.) } \\
\text { F.V.C. (ml.) } \\
\text { P.E.F.R. (1./min.) } \\
\text { P.I.F.R.(1./min.) } \\
\text { F.E.V.1/F.V.C. (\%) } \\
\text { P.E.F.R./P.I.F.R. (\%) }\end{array}$ & $\begin{array}{r}856 \\
2,206 \\
139 \\
168 \\
39 \\
83\end{array}$ & $\begin{array}{r}913 \\
2,459 \\
152 \\
208 \\
37 \\
73\end{array}$ & $\begin{array}{l}\text { N.S. } \\
<0.05 \\
\text { N.S. } \\
<0.001 \\
\text { N.S. } \\
<0.05\end{array}$ \\
\hline
\end{tabular}

\section{Discussion}

\section{Measurement of Inspiratory Resistance}

Airways resistance is most accurately measured by body plethysmography (DuBois et al., 1956). In the absence of such complicated apparatus, and assuming that the respiratory muscles are normal, forced inspiratory volume in one second (F.I.V. $)$ or P.I.F.R. provides indirect measurements of inspiratory resistance. These may be calculated from a spirogram by means of an instrument of suitable frequency response (McNeill et al., 1959). In this study P.I.F.R. was measured with an adapted Wright flow meter which could be calibrated under steady flow conditions and is relatively cheap.

The chief disadvantage of tests which demand forced inspiration is that they are markedly effort-dependent, for flow produced is related closely to the applied transpulmonary pressure. Tests involving forced expiration, on the contrary, are to some extent independent of effort, for the narrowing of airways which occurs on expiration produces a maximum in the flowpressure relation such that (for a given lung volume) increase in pressure above a certain point will not cause a further increase in flow (Fry and Hyatt, 1960). However, in this study withinpatient variance for P.I.F.R. was not excessive, and was not always greater for P.I.F.R. than for P.E.F.R. (Table I).

\section{Inspiratory and Expiratory Resistance in Patients with Airways Obstruction}

In patients with diffuse airways obstruction, narrowing of airways on expiration may be pathologically exaggerated, either because of loss of supporting lung framework or because of intrinsic weakness of the bronchial wall (Dayman, 1951 ; Fry et al., 1954 ; Campbell et al., 1957 ; Dekker and Groen, 1957 ; Gandevia, 1963). These mechanisms account for the increased expiratory resistance in some patients.

Inspiratory resistance may also be increased (Kahana et al., 1963 ; Park, 1965 ; Burrows et al., 1966b). Macklem et al. (1965) showed that there are two sites at which increased resistance to gas flow may occur. Firstly, there may be an abnormally high resistance in the larger segmental bronchi which is present on expiration only, and is caused by airway collapse. Secondly, there may be abnormal resistance in the smaller peripheral airways, present on inspiration as well as expiration. Any bronchospastic element is likely to be localized in the small airways. Relief of spasm by a bronchodilator drug will not prevent airways collapse, though it may alter the site at which it occurs. Macklem and his colleagues suggested that improvement after such therapy may be marked during forced expiration by the collapse of larger and more central airways. Improvement might, however, be detected by tests which employ maximum inspiratory effort, when the large airways will be widened rather than collapsed.

\section{Results of this Study}

The findings reported here are consistent with the hypothesis that the abnormal airways resistance of these patients was due to expiratory collapse of large airways and/or obstruction of small peripheral airways, and that the relative importance of these two mechanisms varied from patient to patient. The small-airway obstruction was partially relieved by isoprenaline in some patients.

In a group of patients with radiological emphysema there was a significant increase in P.I.F.R. and F.V.C. after isoprenaline, but not in P.E.F.R. or F.E.V. . It is suggested that, in the measurement of P.E.F.R. and F.E.V. ${ }_{1}$, airways collapse masked the effect of isoprenaline on smaller peripheral bronchi.

In a second group, without radiological emphysema, P.E.F.R., F.E.V., P.I.F.R., and F.V.C. all increased significantly. It is suggested that airways collapse was not a significant factor in this group.

The significant correlation between changes in P.I.F.R. and changes in F.V.C. (Fig. 3) was an interesting finding. Possibly a decrease in inspiratory resistance enabled the patient to take a deeper breath; this relation needs further investigation.

Patients with chronic airways obstruction have been classified into types $\mathrm{A}$ and $\mathrm{B}$ according to clinical, radiological, and functional criteria (Fletcher et al., 1963 ; Burrows et al., 1964, 1966a). Both types show increased expiratory resistance, but type $B$ patients tend to have a higher inspiratory resistance than type A. Mechanical abnormalities arising from increased smallairway resistance may be responsible for the differences between the two types (Kahana et al., 1963 ; Park, 1965 ; Burrows et al., 1966b). Group 3 patients in this study probably belong to type A ; data for accurate classification are not available. It will be of interest to investigate patterns of bronchodilator response in type A and B subjects, for such patterns might help to distinguish the two types simply.

In epidemiological studies P.E.F.R. and F.E.V., are often used as objective measurements in the long-term follow-up of patients with chronic bronchitis and/or emphysema. Possibly some measurement which reflects inspiratory resistance should also be used in such studies.

\section{Assessment of Bronchodilator Therapy}

This study confirmed that changes in F.E.V. ${ }_{1}$ /F.V.C. are of limited help in assessing the effect of bronchodilator drugs (Stein et al., 1966), for some of the patients showed a disproportionate increase in F.V.C. and a fall in F.E.V. ${ }_{1} /$ F.V.C., while others showed a disproportionate rise in F.E.V. ${ }_{1}$ and a rise in F.E.V. ${ }_{1} /$ F.V.C.

In a group of patients with radiological emphysema isoprenaline caused no improvement in P.E.F.R. or F.E.V. ${ }_{1}$, and, judged by these tests alone, such patients would be said to have " fixed" airways obstruction. However, P.I.F.R. and P.V.C. markedly increased after isoprenaline, suggesting that inspiratory resistance decreased. It seems that lack of response to tests involving forced expiration alone should not be regarded as evidence that bronchodilator drugs are of no benefit to the patient. Response to isoprenaline should ideally be tested with a body plethysmograph, but some simple measurement which reflects changes in inspiratory resistance is helpful. Such measurements will inevitably be effort-dependent, and obsessional care in teaching and supervising subjects will be necessary.

\section{Summary}

Response to bronchodilator therapy has been studied in 30 patients with chronic airways obstruction, both peak expiratory and inspiratory flow rates being used. 
The "within-patient" variance for P.I.F.R. was greater than that for P.E.F.R. over most ranges, but was not excessive.

Change in P.E.F.R. was significantly correlated with change in F.E.V. ${ }_{1}$, but not with change in F.V.C. Change in P.I.F.R. was significantly correlated with change in F.V.C., but not with change in F.E.V. ${ }_{1}$.

In a group of patients without radiological emphysema P.E.F.R., F.E.V., P.I.F.R., and F.V.C. increased significantly after isoprenaline. In a group of patients with radiological einphysema P.I.F.R. and F.V.C. increased significantly but P.E.F.R. and F.E.V..$_{1}$ did not. It is suggested that in the second group expiratory airways collapse may mask the relief of peripheral bronchial spasm by isoprenaline.

Lack of response to isoprenaline when tests of forced expiration are used alone should not be regarded as evidence that bronchodilator drugs are of no benefit to the patient. Measurements of inspiratory flow may prove a more sensitive index of bronchodilator response.

I wish to thank Mr. R. W. Halls for adapting the peak flow meter, Dr. J. W. Pierce for assessing the chest $x$-ray films, Dr. D. A. Mitchison for much help and advice on statistical treatment of the data, and Dr. N. L. Jones for criticism of the manuscript. I am particularly grateful to Dr. C. G. Caro for advice and encouragement throughout this study.
REFERENCES

Burrows, B., Fletcher, C. M., Heard, B. E., Jones, N. L., and Wootliff, J. S. (1966a), Lancet, 1, 830 .

Niden, A. H., Fletcher, C. M., and Jones, N. L. (1964). Amer. Rev. resp. Dis., 90, 14.

Reviksena, F. B., and Diener, C. F. (1966b). Ann. intern. Med., 65, 685.

Campbell, E. J. M., Martin, H. B., and Riley, R L. (1957). Bull. fohns Hopk. Hosp., 101, 329.

Collins, M. M., McDermott, M., and McDermott, T. J. (1964). F. Physiol. (Lond.), 172, 39P.

Dautrebande, L., and Lovejoy, F. W. (1961). Arch. int. Pharmacodyn., $131,230$.

Dayman, H. (1951). 7. clin. Invest., 30, 1175.

Dekker, E., and Groen, J. (1957). Lancet, 1, 1064

DuBois, A. B., Botelho, S. Y., and Comroe, J. H., jun. (1956). F. clin. Invest., $35,327$.

Fletcher, C. M., Hugh-Jones, $P_{\ddot{3},}$ McNicol, M. W., and Pride, N. B. (1963). Quart. F. Med., 32, 33 .

Fry, D. L., Ebert, R. V., Stead, W. W., and Brown, C. C. (1954). Amer. 7. Med., 16, 80 .

- and Hyatt, R. E. (1960). Ibid., 29, 672.

Gandevia, B. (1963). Quart. Ұ. Med., 32, 23.

Kahana, L. M., Aronovitch, M., and Place, R. (1963). Amer. Rev. resp. Dis., 87, 699 .

Laws, J.' W., and Heard, B. E. (1962). Brit. F. Radiol., 35, 750.

Macklem, P., T., Fraser, R. G., and Brown, W. G. (1965). F. clin. Invest.,

44, 897.
McNeill, R. S., Malcolm, G. D., and Rhind Brown, W. (1959). Thorax, $14,225$.

Nairn, J. R.. and McNeill, R. S. (1963). Brit. med. 7., 1, 1321.

Park, S. S. (1965). Amer. Rev. resp. Dis., 92, 245.

Park, S. S. (1965). Amer. Rev. resp. Dis., 92, 245 . It. Iowa.

Snedecor, G. W. (1956). Statistical Methods, 5th ed. Iowa.

Stein, M., Tanabe, G.,

Wright, B. M., and McKerrow, C. B. (1959). Brit. med. F., 2, 1041.

\title{
Hypoxia in Bronchial Asthma
}

\author{
J. A. WADDELL,* M.B., M.R.C.P., M.R.C.P.ED. ; PETER A. EMERSON,* M.A., M.D., F.R.C.P. \\ R. F. GUNSTONE,*† M.B., B.SC., M.R.C.P., M.R.C.P.ED.
}

Brit. med. F., 1967, 2, 402-404

The increased resistance to air flow, bronchial closure, and uneven distribution of ventilation which occurs in bronchial asthma has been extensively described, but relatively little attention has been paid to the effects on the gas exchange and on the arterial blood gas tensions during actual paroxysms of asthma.

The purpose of this paper is to present the results of blood gas studies during and after recovery from acute attacks of asthma severe enough to require steroid therapy; also before and after inhalation of isoprenaline.

\section{Methods}

The patients studied all gave a history of paroxysmal expiratory distress associated with objective evidence of airways obstruction but without conclusive radiological signs of emphysema, nor a history of regular daily sputum production. None of the patients was in cardiac failure ; in many the attacks of dyspnoea appeared to be related to episodes of emotional stress or to the pollen season; they all obtained considerable subjective benefit from bronchodilator drugs, and most had less than grade II dyspnoea during remissions.

The patients were studied initially when in hospital ; the measurements were made in a reclining position. Follow-up measurements were made when the patients appeared to be clinically improved, usually one to three weeks after the first measurements. After an acclimatization period expired air was collected in a Douglas bag for five minutes while three heparin-

\footnotetext{
* Westminster Hospital Teaching Group (Queen Mary's Hospital, London S.W.15).

† Present address: St. George's Hospital, London S.W.17.
}

ized arterial blood samples were slowly withdrawn. The arterial blood oxygen tension $\left(\mathrm{PaO}_{2}\right)$ was measured with a Clark Bishop oxygen electrode which was calibrated with two samples of water equilibrated with known gas mixtures ( $8 \%$ oxygen and $13.3 \%$ oxygen or air). The electrode was also checked against tonometered blood; the mean ratio of $\mathrm{Po}_{2}$ determined in blood to that in water was 1.06 , a figure which agrees closely with that of other laboratories. The arterial carbon dioxide tension $\left(\mathrm{PaCO}_{2}\right)$ was measured with the Astrup micro $\mathrm{pH}$ electrode and microequilibration apparatus. Expired air was analysed with a Haldane apparatus.

The physiological dead space (VD) was calculated from the Bohr formula:

$$
\mathrm{VD}=\frac{\mathrm{VT} \times\left(\mathrm{PaCO}_{2}-\mathrm{PECO}_{2}\right)}{\mathrm{PaCO}_{2}}-\text { apparatus dead space. }
$$

where $\mathrm{VT}=\mathrm{Tidal}$ volume.

$\mathrm{PECO}_{2}=$ Tension of carbon dioxide in expired air.

The "ideal" alveolar oxygen tension $\left(\mathrm{PAO}_{2}\right)$ was calculated from the alveolar air equation:

$$
\mathrm{PAO}_{2}=\mathrm{P}_{1} \mathrm{O}_{2}-\mathrm{PaCO}_{2}\left(\mathrm{~F}_{\mathrm{I}} \mathrm{O}_{2}+\frac{1-\mathrm{F}_{\mathrm{I}} \mathrm{O}_{2}}{\mathrm{R}}\right)
$$

where $\mathrm{P}_{1} \mathrm{O}_{2}=$ Inspired air oxygen tension.

$\mathrm{F}_{1} \mathrm{O}_{2}=$ Fraction of oxygen in inspired air.

$\mathrm{R}=$ Respiratory exchange ratio.

Isoprenaline was administered by Medihaler, and the measurements were repeated immediately without an acclimatiza- 